\title{
The Sustainable Digitalization in the Manufacturing Industry: A Bibliometric Analysis and Research Trend
}

\author{
Zhiming Shang $(\mathbb{D}$ and Liming Zhang \\ Business School, Sichuan University, Chengdu 610064, China \\ Correspondence should be addressed to Liming Zhang; zhangliming@scu.edu.cn
}

Received 5 November 2021; Revised 17 December 2021; Accepted 23 December 2021; Published 18 January 2022

Academic Editor: Hasan Ali Khattak

Copyright (C) 2022 Zhiming Shang and Liming Zhang. This is an open access article distributed under the Creative Commons Attribution License, which permits unrestricted use, distribution, and reproduction in any medium, provided the original work is properly cited.

\begin{abstract}
Digital technologies are shown to perform a vital role in developing a resource-efficient industrial base. The effective adoption of digital technologies can help reduce costs and improve the sustainability and flexibility of manufacturing industries. However, how digital technologies favor the transition towards manufacturing systems has not been analyzed in detail yet, so more conceptual and empirical investigation is required in this field. This study investigates the digital transformation trend in the manufacturing industry by combining the bibliometric method with life cycle mode and literature mining. An integrated data analysis system (IDAS) is developed, which includes data collection, data analysis, and visualization processes. As a result, dualmap overlay, keywords clusters, Timeline, and Time zone views are visualized to identify the research trend with the three main aspects: design, larger integrated circuit, and sustainable manufacturing concept evolution. Besides, to recognize potentials for future development of the domain, life cycle model-based technological trajectory is identified, constructing an information society, the combination of tools, and the performance improvement of the whole digital transformation. Moreover, in response to sustainable development, a system considering business strategies and cultural delivery, technological integration, and partner participation and evaluation is developed, which could cope with complex manufacturing processes due to different industrial tasks in different regions.
\end{abstract}

\section{Introduction}

Digital technology is reshaping the world economy and has become a new driving force for economic growth. New digital technologies offer more innovation and development zones to enterprises and industrial supply chain organizations [1]. Based on the layout of information technology, such as $5 \mathrm{G}$ communication networks, computing centers, industrial Internet platforms, artificial intelligence, blockchain, and cloud computing, digital technologies promote the way of resource allocation in the industrial supply chain, the potential value of labor division, and the form of cooperation. The digital connection breaks the internal and external barriers of the organization, while technological advances can encourage disruptive innovation and alternative competition in the field [2].

Integration of advanced technology and associated digitalization in industries is now becoming essential especially when working towards achieving sustainability within the manufacturing operations. Integration of these advanced technologies is extremely supportive in productivity improvement, waste management, time management, and enhanced competitive advantage. Digitalization is now an essential part of a sustainable manufacturing environment [3]. The development of manufacturing began early $19^{\text {th }}$ century from the first or Victorian industrial revolution, where steam engines were used in manufacturing with supply chain systems. The second industrial revolution presented mass production, and the use of electricity for production. This second-generation industrialization was upgraded with the incorporation of electronics and robotics into the manufacturing process [4]. The desire to make it more sustainable has resulted in the evolution of the fourth industrial revolution (I4.0), which upgraded the third industrial revolution with the integration of information and 
communication technology (ICT) that comprises digitalization, cyber-physical systems, artificial intelligence, and data analytics for improved productivity [5].

In real-world practice, the manufacturing industry has continued its digital transformation. According to the White paper "The Impact of the Fourth Industrial Revolution on Supply Chains" released by the World Economic Forum, the digital transformation would reduce the cost of manufacturing enterprises by $17.6 \%$ and increase the revenue by $22.6 \%$ [6]. However, challenges have been derived from the changing technological landscape. The first challenge is culture change and employees management in enterprises. Araujo et al. [7] proved a strong link between digital leadership and corporate success and productivity. Business leaders in the manufacturing industry are advancing digital transformation and changing their strategic thinking. It is known that business leaders must not only profoundly understand the impact of digital systems, but also promote the development of digital virtual systems for enterprises, and they must communicate effectively with employees and consumers under the big-data situation [8]. In other words, culture change and associated behavioral changes are the main hurdles in the manufacturing industry [9]. Meanwhile, these hurdles have attracted industrial research. Frank et al. [10] proposed that a new skill set is required to effectively lead the organization into an uncertain, more dynamic future. Hence, devising mechanisms for realizing leadership in the digital age have a profound need [11]. However, there is less research on the manufacturing industry.

The second challenge is technological advances and choices. The I4.0 is considered to be the cornerstone of digital transformation in industries. After the advent of Information Technologies (ITs) in the manufacturing industry, it makes factories more intelligent and have increased ergonomics, adaptability, and resource efficiency. In Sweden, the metal industry has made efforts on digital leap [12]. The United States government invested 70 million US dollars in 2014 to create a digital laboratory for digital manufacturing and innovation, which enabled real-time collaboration and big data analysis during manufacturing production processes [13]. Digitalization changes the manner of the operational linking chain, and it has undoubtedly promoted productivity $[14,15]$. However, the digitization of manufacturing offers diverse opportunities and challenges in terms of the progress of investment in technological advances. Although the abovementioned literature review provides valuable information on the state of the literature on sustainability and digitalization, there is still much need for a bibliometric approach for analyzing this literature. Hence, faced with the complex industrial processes due to different tasks in different regions, this study identifies the pathways and evaluation index for sustainable digital transformation in the manufacturing industry.

The study analyzes the manufacturing industry's digital transformation based on an IDAS and concludes the research streams. It also recognizes the major processes employed in the incorporation of digital transformation into the enterprise. The study also determines the environment required for the popularization of digitalization in the manufacturing industry, and how to build it facing complex industrial processes due to different tasks. Moreover, the study identifies the basic architecture framework and shared principles for the digitalization of the manufacturing process.

The remainder of this paper is listed as follows: Section 2 describes the proposed research methodology. Section 3 reveals the current research on digital transformation in terms of the manufacturing industry. Section 4 evaluates the evaluation dimensions of a sustainable digital transformation support system in the manufacturing industry, and several essential contents for the development are given. Finally, Section 5 concludes the whole study.

\section{Methodology}

2.1. Integrated Data Analysis System (IDAS). An IDAS based on bibliometric and literature mining was developed to focus on digital transformation in manufacturing industry analysis. The IDAS includes data collection, data analysis, and visualization processes.

As a comprehensive integrated approach to elucidate keyword trends, the IDAS was developed from the Web of Science Core Collection (WoS-CC), and CiteSpace to guide the research towards retrospective analysis and policy-based management development trajectories. The major steps in this process are depicted in Figure 1.

The data were collected in July 2021, with the retrieval period being from 1990 to 2020. The search strings were T.S. $=($ Digital transformation OR Digital Transition $)$ AND $\mathrm{TS}=$ (manufacture industry OR manufacturing industry). After refining articles from the searched papers, the WOS covers 510 in its core database. When the search was complete, all related articles were downloaded and saved in CiteSpace. CiteSpace is a commonly used statistical analysis tool based on the Java environment, designed by Synnestvedt et al. [16].

2.2. Data Classification and Visualization Analysis. Data classification and visualization are essential to assist the analyst in quickly identifying data trends. The pictorial representation of datasets permits analysts to visualize concepts and new patterns. In this study, the parameters are set as time slices from 1990 to 2020, the networks are constructed using the "minimum spanning tree (MST)" pruning algorithm, and keywords are defined as the node. Different network analysis views such as dual-map overlay, cluster, Timeline, and Time zone are depicted as shown in Table 1.

2.2.1. A Dual-Map Overlay. The dual-map overlay reveals patterns of a scientific portfolio with respect to a global map of scientific literature [17]. It presents the details in citation links and cited fields as shown in Figure 2. From left to right, the colored curve presents the citing path, where the citing trajectory is shown on the left of the dual map, and the cited trajectory is shown on the right. The 


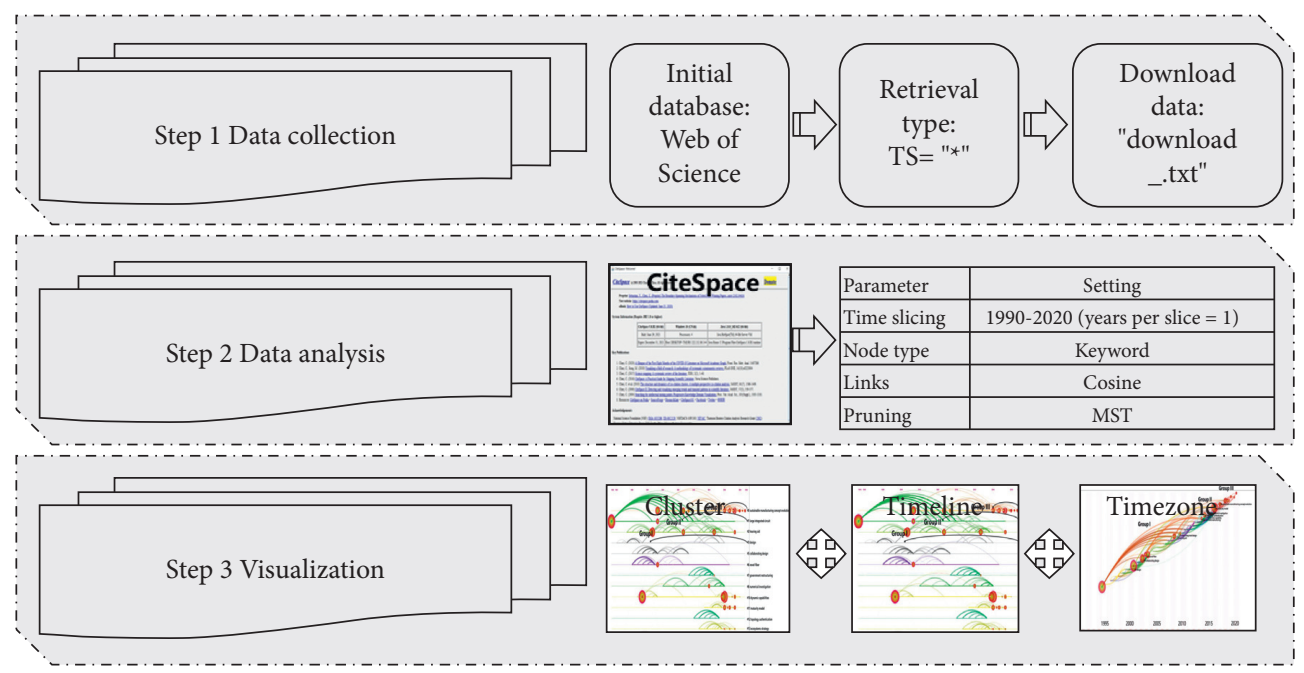

FIGURE 1: The process of literature refinement and visual analysis.

TABLE 1: Parameters setting in this study.

\begin{tabular}{lc}
\hline Parameter & Setting \\
\hline Time slicing & $1990-2020$ (years per slice $=1$ ) \\
Node type & Keyword \\
Links & Cosine \\
Pruning & Minimum spanning tree \\
Visualization & Cluster view, time zone, and timeline views \\
\hline
\end{tabular}

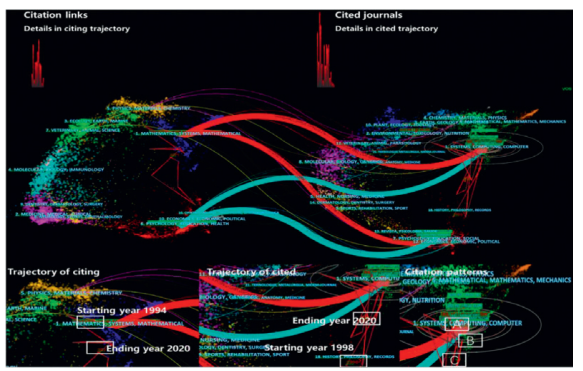

Figure 2: Dual-map overlay for final document storage.

size of the circle on the left is determined by the published number of articles in one field. The citing-cited link reflects that digital transformation in the manufacturing industry moves from field labeled as "mathematics, system, mathematical" to the field labeled as "system, computing, computer," and "economics, economic, political." Based on the results of what types of the journal are cited, the dual-map overlay implies that it is possible to move digital transformation in the manufacturing industry from traditional mathematical research field to a range of policy- and user-oriented concerns fields. To sum up, it is a combination of mathematical, management, and economics sciences with respect to the design and utilization of computer-based models as tools for transferring knowledge from science to policy. To be specific, for the digital transformation in the manufacturing industry, the research trend is transferring scientific information from mathematical modeling to social policy.
2.2.2. Visualization of the Scientific Literature from Different Dimensions. A cooccurrence map (feature term, keyword, and subject category) is drawn as follows: This study takes modularity and silhouette as the two key indexes to evaluate and identify the structural networks' properties derived from CiteSpace. It is found that the modularity value is 0.8698 , as shown in Figure 3, which is a relatively high value and reflects the reasonability of the clustering network. Besides, Weighted Mean Silhouette is used for measuring the clustering effect of the data. If the Weighted Mean Silhouette value is around 1, the cluster results are reasonable, while if it is around -1 , the cluster results are not reasonable. If the value is equal to 1 , it represents a perfect result [18]. It is on the two clusters' boundary if the Weighted Mean Silhouette value is equal to 0 . The index in this study is calculated as 0.9549 , which shows that the digital transformation in the manufacturing industry is relatively high.

The network consists of 846 nodes and 929 links. 55 cooccurrence clusters are identified based on the principle of auto-labeling. We choose three clusters based on the side and Weighted Mean Silhouette value, that is, "sustainable manufacturing concept evolution (\#0)," "larger integrated circuit (\#1)," and design (\#3). Cluster 0 has 76 members, and the most active citation is Culot et al. [19], cluster 1 has 58 members, with the most active citation being Ranky et al. [20], and cluster 3 has 47 members, and the most active citation is Fountain [21]. These three papers with a high level of citing times are analyzed in Table 2, which shows a research trend over time. Further, based on the previous articles, we divided the whole study into three groups from a 


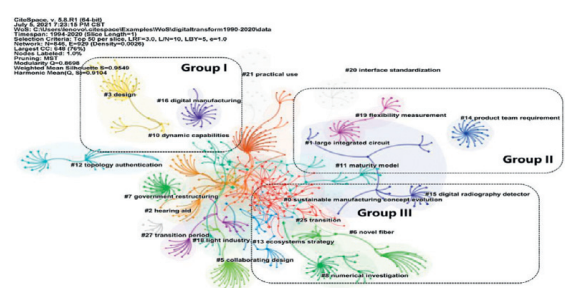

FIGURE 3: Keyword cooccurrence and cluster results. CiteSpace configuration: $\mathrm{LRF}=3, \mathrm{LBY}=10, e=1.0$, and top 50 per slice.

TABLE 2: Literature review of the most active citations.

\begin{tabular}{lcc}
\hline Article & Year & Main points \\
\hline Fountain [21] & 2020 & Novel leadership in digital information processing \\
Ranky et al. [20] & 2003 & Managing manufacturing lines and providing electronic support systems for operators \\
Culot et al. [19] & 2000 & Operationalization of industry 4.0 across multiple disciplines \\
\hline
\end{tabular}

time side, as shown in Table 3. The mean (year) presents digital transformation in manufacturing industry development that first appeared in cluster 3 (2001), then in cluster 1 (2008), and then in cluster 0 (2016), with the burst of these three clusters consisting of different stages. The content of the first stage is about constructing an information society, the second stage is concerned with the combination of decision-making tools, and the third stage focuses on the performance improvement of the whole digital transformation.

Figures 4 and 5 show the cluster results from the perspective of Timeline and Time zone. From the Timeline side, it elaborates clusters with horizontal timelines. The color in the center of the nodes represents the time of the literature to be cited for the first time, whereas the exterior of the central part represents other times of being cited, corresponding to the color of the timeline above the pattern. The radius of the nodes indicates the frequency of the literature to be cited by others. The bigger the radius is, the more frequent the literature is cited. The key nodes are surrounded by purple rings, connecting more than two different clusters in most cases. They are the nodes with a high centrality $\dagger$ degree and frequency of being cited $[5,22]$.

Then, a research trend diagram was generated in a time zone view to identify the research trend over time. The lines between every ring show the connecting relationship between the two articles. The rings' color represents the burst's hotness, and the ring's size represents the frequency of being cited. The site of each ring center stands for the publishing time in the horizontal position.

As can be seen in Figures 4 and 5, clusters changing trends are depicted during specific periods: "design" is followed by "larger integrated circuit" and, then, "sustainable manufacturing concept evolution," thus revealing the digital transformation in the manufacturing industry. Based on this initial analysis, three digital transformations in manufacturing industry phases are identified.

The country collaboration network is analyzed to examine the answer to "Who researches in digital transformation in the manufacturing industry?" given by Zhong et al. [23]. We found that 71 of the publications were contributed by teams including German researchers, followed by teams including authors from the USA (46 publications), Italy (40 publications), and China (34 publications).

The details are shown in Figure 6. In addition, it describes that Germany, USA, and France are active in the country's collaboration network with other countries/regions, while the node of Italy with the higher centrality is recently found. In general, the results point out that digital transformation in the manufacturing industry is mainly studied in Europe and America continents while becoming a hotspot in many countries across the globe recently.

2.3. Life Cycle Mode-Based Technological Trajectory. We analyzed the evolutionary stages in terms of digital transformation in the manufacturing industry based on technological life cycle mode. It helps identify the research trajectory and recognize potentials for future development of the domain. In this stage, the content of the first stage is about constructing an information society, the second stage is associated with the combination of tools, and the third stage focuses on the performance improvement of the whole digital transformation. Based on the idea of Kuhn [24], this study elaborates them as shown in Figure 7.

Stage I is to answer many research questions. Technological opportunities are very high in this stage. Data science technology has brought opportunities for upgrading traditional manufacturing processes. Data-driven companies could fully consider customer interaction, process control, and cooperation methods, enabling modern companies to create advantages in data-based production. Existing research has paid attention to the driving role of data technology in several areas, such as promoting production innovation, interactive identification, and flexible and agile process. However, in this stage, it lacks research on the integrated concern, such as methods for decision analysis, dynamic simulation and network analysis to auto- and lowcost operation process of inventory control, supply chain coordination optimization, equipment resources, and human resource management under the "Everything is Number" rule, and then formulating the "optimum" resources in the production process. Hence, how digital 
TABLE 3: A list of selected clusters.

\begin{tabular}{lccccc}
\hline Cluster ID & Size & Silhouette & Mean (year) & Label (LLR) & Label (label (TF * DF) \\
\hline 0 & 76 & 0.837 & 2016 & Sustainable manufacturing concept evolution & Digital transformation \\
1 & 58 & 0.948 & 2008 & Larger integrated circuit & Decision-making tool \\
3 & 47 & 1.000 & 2001 & Design & Constructing the information society \\
\hline
\end{tabular}

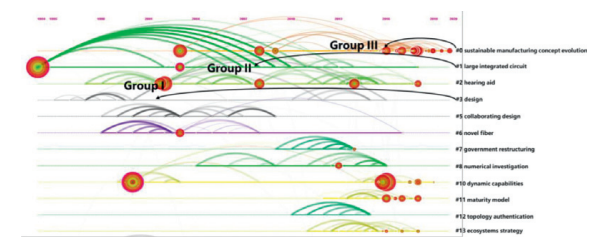

FIgURE 4: Cluster results with a timeline view.

technology drives production innovation is carried on to the next stage.

Stage II focuses on the development and combination of research models and tools. This stage generally considers two aspects: first, mining the internal mechanism of digital transformation towards production innovation; second, management paradigm and digitalization. These existing researches comprehensively explore the internal mechanism that promotes digitalization from the customer, process, cooperation, employee, and leader levels and distinguishes the role of different levels in the transformation of digitalization.

Stage III contributes to a specialty, which focuses on decision support. To approach the smart manufacturing industry, this is a "how to be better" stage. The digital transformation itself is a complex system engineering, not just as simple as introducing advanced management tools in the production process. Only by designing the data operation architecture and synergistically empowering from the level of customers, processes, cooperation, employees, and employer can enterprises realize the advantages of digitalization.

\section{Manufacturing Industry's Digital Transformation Trend}

To promote the manufacturing industry's digital transformation and contribute to the existing research in digital transformation and the manufacturing industry, the IDAS unfolds the basic keywords of current research and implies the future research trend. In the following sections, the research paradigm is summarized.

3.1. Importance of Information Society Construction. In the information age, the Internet and World Wide Web have improved collaboration and approached disintermediation with less burdensome. Besides, designers affect enterprises through ITs in ways that consumers prefer. To be specific, IT, acting as a platform and tool, digitally enhances consumer, partner, and operational agilities [25]. Thus, consumer agility enables satisfaction improvement. Likewise, the partner agility enables efficient cooperation and contributes to a win-win situation, and operational agility achieves flexibility and benefits. Table 4 reviews several articles and illustrated the necessity of information society construction.

Recently, industry 4.0 has attracted much attention in recent literature since it was originally initiated in Germany in 2011. Under the high-tech push situation, several capacities are needed, including short manufacturing periods, consumerization, flexibility, efficient cooperation, resource sustainability, and fast decision-making procedures. Further, extensive approaches of a technology-push information society (IS) are identified to include autonomous manufacturing, digitalization, and miniaturization in the context of the "I4.0" project [35]. Faced with the extensive approach of the "Industry 4.0" project, manufacturing industries stakeholders are thinking strategies. As we know, digital manufacturing enables the use of advanced and suitable ITs to transform the entire production into a more efficient, flexible, and sustainable production process. Hence, information society construction is the first step for digitalization in the manufacturing industry. Additionally, digital technologies' fusion speeds the construction of information society.

3.2. Digital Business Strategy and Systematic Integration. Recently, enterprises in almost all industries, especially manufacturing industries, have made efforts to apply new digital technologies and pursue revenue while reducing economic costs. The existing IS consists of new digital technologies, data, real-world production applications, and employers who apply technologies to create value. Hence, it can be concluded that IS composites not only technological factors, but also human activities.

I4.0 built the bridge for technological advances in manufacturing industries. I4.0 is not hype but an integrated practice. Key technological factors include 5G, agent-based systems, smart factories [36]. Manufacturers must get on board as soon as possible. Long before that, Porter and Millar [37] presented the advantage of the information in the industrial value chain, and then Vega-Jurado et al. [38] proved the positive relationship between technology acquisition and firms' innovative performance. Meanwhile, big data technology improved predictive capacity, prevented 


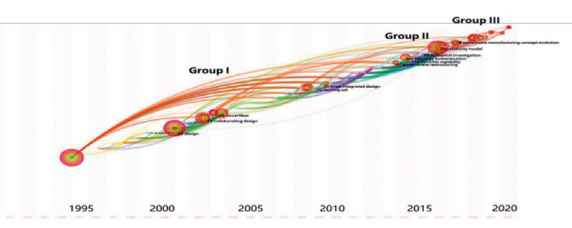

Figure 5: Cluster results with time zone view.



FIGURE 6: Country collaboration network.


FIGURE 7: Digital transformation in manufacturing industry paradigm evolution.

asset breakdowns, and further made the production process more effective. Human activities help in identifying optimal production planning based on the predefined strategy. Besides, the interaction between individuals and the IS-based management environments helps advance the performance of leaders and employers.

Further, the combination of digital transformation and strategy in management leads to a new term, "digital business strategy" [39]. The digital transformation explores the potentials for the application of integrated digital technologies for factories and industries. Later, scholars have explored the effect of big data in competitive areas, as shown in Table 5.

It can be concluded that digital transformation strategy is a blueprint that supports companies in governing the transformations that arise owing to the integration of digital technologies, as well as in their operations after a transformation. Hence, leaders need to find out the new business norm to digitally reimagine the business with a set of digital strategies. In this way, the new competitive advantage of the manufacturing industry can be invented.

3.3. Future of Digitalization in the Manufacturing Industry. It is known that the industrial environment affects management, which can be defined as industrial dynamism, competition, and munificence environment [45]. Nowadays, organizations need to adapt to integrating these digital technologies and leaders' capabilities to transform processes, attract talent, and promote new business models to compete and fight in the digital world.

Some scholars have conducted an empirical analysis to find customized ways to improve the construction of digital business strategy and planning in manufacturing industries (as shown in Table 6). Moreover, Ukko et al. [49] empirically examined the impact of a sustainability strategy on the 
TABLE 4: Literature review in terms of information society construction.

\begin{tabular}{|c|c|}
\hline Articles & Main points \\
\hline Weill and Vitale [26] & $\begin{array}{c}\text { Defined the contents of IT and illustrated its impact on business models, and proved the active effect of IT on } \\
\text { business support. }\end{array}$ \\
\hline Kraemer et al. [27] & $\begin{array}{l}\text { Studied Dell's case and proposed a new mechanism of IT, which helped reduce costs, update the speed of } \\
\text { production, and enhance the competition and attractiveness. }\end{array}$ \\
\hline Zhu [3] & $\begin{array}{c}\text { Empirically proved the positive correlation between IT infrastructure and the e-commerce development in the } \\
\text { retailer sector. }\end{array}$ \\
\hline Saraf et al. [28] & $\begin{array}{c}\text { Proved two major roles for IT on relationships between companies, that is, upstream-downstream production } \\
\text { processes and knowledge management. }\end{array}$ \\
\hline Chryssolouris et al. [29] & $\begin{array}{l}\text { Discussed several technologies in the digital factory and manufacturing concepts, and supported that digital } \\
\text { manufacturing was beneficial for time and cost reduction, customization, quality improvement, etc. }\end{array}$ \\
\hline Westerman et al. [30] & $\begin{array}{l}\text { Illustrated the necessity of transforming manufacturing processes through digitization and proved that the } \\
\text { development lifecycle is decreased by } 30 \% \text { after digitalization. }\end{array}$ \\
\hline Hanelt et al. [31] & $\begin{array}{c}\text { Conducted a rigorous analysis of digital transformation for traditional physical industries, and illustrated several } \\
\text { barriers for digitizing automotive products. }\end{array}$ \\
\hline Martin [32] & Proved the enhancement of productivity in manufacturing with the growth of IT. \\
\hline Ziemba [33] & $\begin{array}{c}\text { Empirically studied the correlation between IT adoption in enterprises and the improvement of sustainable } \\
\text { information society. }\end{array}$ \\
\hline $\begin{array}{l}\text { Castelo-Branco et al. } \\
\text { [34] }\end{array}$ & Offered evidence about how digital infrastructure in the manufacturing sector and big data capabilities coexist. \\
\hline Articles & ints \\
\hline $\begin{array}{l}\text { Doll and Vonderembse } \\
\text { [40] }\end{array}$ & Proved that IS led to the integration of computer technologies in the manufacturing industry \\
\hline Merali et al. [41] & Analyzed the technological advances in th \\
\hline Qi et al. [42] & $\begin{array}{c}\text { Empirically explored the collaborative strategy's effect on lowering costs and increasing efficiency, based on } \\
\text { Chinese manufacturers' data }\end{array}$ \\
\hline $\begin{array}{l}\text { Qrunfleh and Tarafdar } \\
\text { [43] }\end{array}$ & $\begin{array}{l}\text { Theoretically explained and empirically examined how IS strategies can be gainfully accompanied by different } \\
\text { types of supply chains }\end{array}$ \\
\hline Paschou et al. [44] & $\begin{array}{c}\text { Conducted a literature review on the nascent research area, and conceptualized and provided insights on digital } \\
\text { servitization }\end{array}$ \\
\hline
\end{tabular}

TABLe 6: Cases analysis and practical implications.

\begin{tabular}{|c|c|c|}
\hline Articles & Case description & Key findings \\
\hline Mahut et al. [46] & Free-floating scooter sharing services & $\begin{array}{c}\text { Technological changes to traditional vehicle manufacturing; and } \\
\text { information sharing helps to find availability provider path and } \\
\text { improve customers' satisfaction }\end{array}$ \\
\hline Ardolino et al. [17] & Intelligent systems with remote control & $\begin{array}{l}\text { Illustrated the necessity of the } \\
\text { relevant for IoT architecture an }\end{array}$ \\
\hline Grubic [47] & $\begin{array}{l}\text { Four manufacturing companies (aero } \\
\text { equipment, marine, and transportat }\end{array}$ & $\begin{array}{l}\text { Information and communication tech } \\
\text { manufacturing industry to the }\end{array}$ \\
\hline $\begin{array}{l}\text { Rymaszewska } \\
\text { et al. [48] }\end{array}$ & $\begin{array}{l}\text { Cases in manufacturing companies (metal } \\
\text { processing, power generation, and distribution) }\end{array}$ & $\begin{array}{l}\text { Different IoT-based solutions enable to build the product-service } \\
\text { systems intelligently from the perspective of new opportunities for } \\
\text { value creation }\end{array}$ \\
\hline
\end{tabular}

relationship between a digital business strategy and financial performance. Qrunfleh and Tarafdar [43] proposed two strategies, "IS for efficiency" and "IS for Flexibility," to improve supply chain performance and firm performance.

To sum up, comprehensive integration is between technologies choice and integration, and human resources. Coevolution of digital and social technologies is fundamental. To understand how to formulate, implement, and evaluate digital business strategies, this study directs several questions for further exploration: (i) What forms of organization, leaders, and employees are needed to form and cultivate and to benefit from digitalization facing different industrial processes? (ii) What challenges and opportunities would exist in the changing environment? (iii) What kinds of integrated technologies, leaderships, and strategies are needed? 


\section{Discussion}

This study explores the potential significance of adopting digital technologies towards specific competitive dimensions and evaluates and analyzes differences about varying company characteristics and the conceptual framework. Although several articles studied digital transformation in manufacturing industries, further analysis on the sustainable digitalization support system for manufacturing industries is needed. Efficiency, sustainability, and international competitiveness are four element aspects for the construction of a sustainable digitalization support system. Efficiency is the foundation of IS. There are two aspects reflecting efficiency, reducing time (such as development time and time-toconsumers), and reducing costs (such as value chain and manufacturing processes). What is more, there are three characteristics for an efficiency-oriented digital transformation in manufacturing industries, including operating processes, leadership and communication, and risk avoidance. Based on the three terms, this study further rechecks the relationship between business model innovation and digital tactics. Wee et al. [4] tried to find out digital advances to seek new ways to enhance internal manufacturing processes. From the intracompany perspective, real-time IS integrates with business processes to ensure meaningful use [14]. From the interconnection perspective, information flow across the whole value chain is vital, of which communication efficiency enhances the data sharing process in IS and further drives all the partners' coordination action [50]. Based on IT development, by taking advantage of the information under complex real-world simulations from all over the chain, most manufacturers can enhance efficiency by optimizing their overall production and quality settings while reducing assets. Also, the cost of the complexity is expected to decline significantly through the increasing elasticity due to the IS development that can be used throughout the value chain [51]. In summary, when considering building a sustainable digitalization support system for the manufacturing industry, efficiency is incorporated in all aspects of the business model and strategy.

Sustainability is a complex and far concept. In the long term, Lozano [52] thought that knowledge of sustainability helps reduce current and future economic disparities, environmental degradation, and social ailments. Besides, sustainability should be integrated into organizational goals, internal incentives and evaluation systems, and organizational decision support systems. Finally, in terms of shaping sustainability regulatory policies, Amini and Bienstock [1] thought that the incorporation of economic, environmental, and social concerns in strategic decisions and design processes is vital.

In the digital era, manufacturing industries must decide in real-time and predict failures in time. It is known that the circular economy strategy benefits reducing, reusing, recycling, and restoring industrial symbiosis. Besides, a digital circular economy seems like a cornerstone of a sustainable society [53]. However, the relation between manufacturing sustainability and potentially future digital technologies is not well established [54]. In other words, there is no clear description of a sustainable digitalization support system. Thus, for the evolution of sustainable manufacturing industries, a long-term dynamic state is needed. A sustainable digitalization support system focusing on manufacturing considers not only specific strategy (e.g., circular strategy, supply chain management), but also organizational structure and business models. Moreover, distinguished leaders have access to integrate all potential digital technologies instead of only one specific technology. For future research, the feasibility and applicability of the digitalization support system in manufacturing industries should have the capacity of supporting adoption at any stages of maturity, such as data transformation/analytics levels, resource optimization stages, and data flow processes.

Digitalization transforms manufacturing industries' business model design and decision-making tools from the traditional "make-and-sell" model into a "sense-and-act" model. Two characteristics refer to the competitive position of manufacturing industries considering digitalization: zero marginal cost of replicated work and zero communication gap [55]. Moreover, there is a network governing the development and evaluation of digital transformation strategies around the competitiveness aspect. These five key dimensions include partner network, core competitiveness, value proposition, distribution channels, and target consumers. Partner network concerns on and promotes value proposition. Core competitiveness also supports the value proposition. In addition, developing measures to strengthen the competitive position of the manufacturing industry by increasing its digital competitiveness is considered an approach. Further distribution channels help deliver products and services to target consumers. Consumers' satisfaction degree gives back to the value proposition and governs the promotion of partner network and core competitiveness.

There are three elements for manufacturers to consider during digital transformation, that is, business strategy, ITs and evaluation, and promotion. In the specific implementation, we have two dimensions: one is the business dimension, which uses IT, and the other is the cultural delivery dimension. Building a sociotechnical system is based on a cultural organization [56]. Value creation and delivery across partners help enhance the efficiency and sustainability of an industry. However, there is no guaranteed answer to who is in charge of digital transformation in manufacturing industries. Digital transformation strategy may be likely to be resisted by various divisions of a company or partners. Hence, to counter this resistance, leadership skills for cultural delivery are necessary and required for the coordination across partners.

The technical aspect is essential for the sustainable digitalization support system. Digital technology reduces cycle times of innovation. Chapman and Kihn [57] proved the positive influence of IT integration on financial performance. Maiga et al. [58] suggested that manufacturing industries would reap financial benefits by investing in cost control systems and IT integration. Digital technological integration leads to a sustainable digitalization support system. For example, " $5 \mathrm{G}+$ Industrial Internet" has been applied to 37 key industries of the national economy, such as 
raw materials and equipment manufacturing. The application scenario is extending from peripheral links such as sales and logistics to internal links such as research and development, production control, and quality monitor [59]. It is considered as one of the necessary conditions for a country to form a new development pattern and effectively promote the high-quality development of the manufacturing industry. Intelligent manufacturing realizes the advanced production mode that utilizes artificial intelligence, 5G, blockchain, VR/AR, and other new-generation information technology to deeply integrate with advanced manufacturing technology, aiming to improve the quality and core competitiveness of the manufacturing industry.

In industries, there are three dimensions for performance evaluation, that is, efficiency, sustainability, and competitiveness. Digitalization is involved in several steps from input to production and output. Input considers human resources, digital technology, and communication. Production refers to intracompany manufacturing and intercompany production. Output is considered as digital services and products selling to the market. In the future, performance quantification is fundamental. Besides, the impact of moderators, such as who takes charge of digital transformation, and the integration degree of digital technologies, should be studied.

In a word, digital transformation and evaluation are a closed cycle, which should be investigated comprehensively. With better management, manufacturers can reduce production cost and time, enhance partners' communication across the life cycle, and achieve sustainability.

\section{Conclusions}

The digital economy has been reshaping the world economy, behind which the digital technology integration pushes it to be applied to more industries. Many countries have made efforts for the improvement of digitalization speed in the manufacturing industry. However, there were several challenges in the context of digitalization, which were mainly concluded as enterprises' culture change and employees' management, and technological advances and choices. Hence, to secure digital transformation in the manufacturing industry in the future, it is needed to build a sustainable digitalization support system, facing complex manufacturing processes due to different industrial tasks in different regions. This study explores the trend of digital transformation in manufacturing industries with the help of an integrated data analysis system, which includes data collection, data analysis, and visualization processes. The dual-map overlay, keywords clusters, Timeline, and Time zone views were visualized to locate the research trend with the three main aspects: design, larger integrated circuit, and sustainable manufacturing concept evolution. Moreover, in response to sustainable development, a system considering business policies and cultural delivery, technical integration, and partner participation and evaluation is established, which could deal with complex industrial processes due to diverse industrial tasks in different regions. For further performance evaluation, efficiency, sustainability, and competitiveness were proposed and can be quantified in the future for performance improvement.

\section{Data Availability}

The data used to support the findings of this study are available from the corresponding author upon request. The software application or custom code is available from the corresponding author upon reasonable request.

\section{Ethical Approval}

There is no ethics-related information.

\section{Consent}

The authors are free to contact any of the people involved in the research to seek further clarification and information. This manuscript has not been published or presented elsewhere in part or entirety and is not under consideration by another journal.

\section{Conflicts of Interest}

The authors declare that they have no conflicts of interest.

\section{Authors' Contributions}

Material preparation, data collection, and results analysis were performed by Zhiming Shang and Liming Zhang.

\section{References}

[1] M. Amini and C. C. Bienstock, "Corporate sustainability: an integrative definition and framework to evaluate corporate practice and guide academic research," Journal of Cleaner Production, vol. 76, pp. 12-19, 2014.

[2] L. Ardito, A. M. Petruzzelli, U. Panniello, and A. C. Garavelli, “Towards industry 4.0," Business Process Management Journal, vol. 25, no. 2, pp. 323-346, 2019.

[3] K. Zhu, "The complementarity of information technology infrastructure and e-commerce capability: a resource-based assessment of their business value," Journal of Management Information Systems, vol. 21, no. 1, pp. 167-202, 2004.

[4] D. Wee, R. Kelly, J. Cattel, and M. Breunig, Industry 4.0-How to Navigate Digitization of the Manufacturing Sector, vol. 58, pp. 7-11, McKinsey \& Company, New York, NY, USA, 2015.

[5] Q. Xu, W. Zhang, L. Hu, J. Wang, and J. Jin, "The development and research of bioinformatics in neuroscience," AASRI Procedia, vol. 1, pp. 359-364, 2012.

[6] World Economic Forum, The Impact of the Fourth Industrial Revolution on Supply Chains, World Economic Forum, Cologny, Switzerland, 2017, https://www.weforum.org/ whitepapers/impact-of-the-fourth-industrial-revolution-onsupply-chains.

[7] D. Araujo, L. M. Priadana, S. Paramarta, and D. Sunarsi, "Digital leadership in business organizations: an overview," International journal of Educationa Administration and leadership, vol. 2, no. 1, pp. 45-56, 2021.

[8] G. C. Kane, D. Palmer, A. Nguyen-Phillips, D. Kiron, and N. Buckley, "Achieving digital maturity," MIT Sloan Management Review, vol. 59, no. 1, pp. 27-34, 2017. 
[9] P. Mugge, H. Abbu, T. L. Michaelis, A. Kwiatkowski, and G. Gudergan, "Patterns of digitization," Research-Technology Management, vol. 63, no. 2, pp. 27-35, 2020.

[10] A. G. Frank, G. H. S. Mendes, N. F. Ayala, and A. Ghezzi, "Servitization and Industry 4.0 convergence in the digital transformation of product firms: a business model innovation perspective," Technological Forecasting and Social Change, vol. 141, pp. 341-351, 2019.

[11] G. Gudergan and A. Buschmeyer, "Key aspects of strategy and leadership for business transformation," The Business Transformation Journal, vol. 11, no. 11, pp. 17-27, 2014.

[12] J. Johansson, I. Asztalos Morell, and E. Lindell, "Gendering the digitalized metal industry," Gender, Work and Organization, vol. 27, no. 6, pp. 1321-1345, 2020.

[13] A. Isakson, T. Peters, J. Harris, and M. Malone, US Department of Defense Awards $\$ 70$ Million Grant to UI LABS-Led Team, White Paper, UILAB, Chicago, IL, USA, 2014.

[14] H. Kagermann, "Change through digitization-value creation in the age of industry 4.0," in Management of Permanent Change, pp. 23-45, Springer Gabler, Wiesbaden, Germany, 2015.

[15] A. Schumacher, W. Sihn, and S. Erol, "Automation, digitization and digitalization and their implications for manufacturing processes," in Proceedings of the Innovation and Sustainability Conference, Burkarest, Romania, 2016.

[16] M. B. Synnestvedt, C. Chen, and J. H. Holmes, "CiteSpace II: visualization and knowledge discovery in bibliographic databases," American Medical Informatics Association, vol. 724, 2005.

[17] M. Ardolino, M. Rapaccini, N. Saccani, P. Gaiardelli, G. Crespi, and C. Ruggeri, "The role of digital technologies for the service transformation of industrial companies," International Journal of Production Research, vol. 56, no. 6, pp. 2116-2132, 2018.

[18] R. F. Babiceanu and R. Seker, "Big data and virtualization for manufacturing cyber-physical systems: a survey of the current status and future outlook," Computers in Industry, vol. 81, pp. 128-137, 2016.

[19] G. Culot, G. Nassimbeni, G. Orzes, and M. Sartor, "Behind the definition of Industry 4.0: analysis and open questions," International Journal of Production Economics, vol. 226, Article ID 107617, 2020.

[20] P. G. Ranky, M. Lonkar, and S. Chamyvelumani, “Transition models of collaborating design and manufacturing enterprises," International Journal of Computer Integrated Manufacturing, vol. 16, no. 4-5, pp. 255-266, 2003.

[21] J. E. Fountain, "Constructing the information society: women, information technology, and design," Technology in Society, vol. 22, no. 1, pp. 45-62, 2003.

[22] L. Wang and G. Wang, "Big data in cyber-physical systems, digital manufacturing and industry 4.0," International Journal of Engineering and Manufacturing (IJEM), vol. 6, no. 4, pp. 1-8, 2016.

[23] S. Zhong, R. Chen, F. Song, and Y. Xu, "Knowledge mapping of carbon footprint research in a LCA perspective: a visual analysis using CiteSpace," Processes, vol. 7, no. 11, p. 818, 2019.

[24] T. Kuhn, The Structure of Scientific Revolutions, Princeton University Press, Princeton, NJ, USA, 1962.

[25] V. Sambamurthy, A. Bharadwaj, and V. Grover, "Shaping agility through digital options: reconceptualizing the role of information technology in contemporary firms," MIS Quarterly, vol. 27, no. 2, pp. 237-263, 2003.
[26] P. Weill and M. Vitale, "What I.T. infrastructure capabilities are needed to implement e-business models," MIS Quarterly, vol. 1, no. 1, p. 17, 2002.

[27] K. L. Kraemer, J. Dedrick, and S. Yamashiro, "Refining and extending the business model with information technology: dell computer corporation," The Information Society, vol. 16, no. 1, pp. 5-21, 2000.

[28] N. Saraf, C. S. Langdon, and S. Gosain, "IS application capabilities and relational value in interfirm partnerships," Information Systems Research, vol. 18, no. 3, pp. 320-339, 2007.

[29] G. Chryssolouris, D. Mavrikios, N. Papakostas, D. Mourtzis, G. Michalos, and K. Georgoulias, "Digital manufacturing: history, perspectives, and outlook," Proceedings of the Institution of Mechanical Engineers, vol. 223, no. 5, pp. 451-462, 2009.

[30] G. Westerman, D. Bonnet, and A. McAfee, “The nine elements of digital transformation," MIT Sloan Management Review, vol. 55, no. 3, pp. 1-6, 2014.

[31] A. Hanelt, E. Piccinini, R. W. Gregory, B. Hildebrandt, and L. M. Kolbe, "Digital transformation of primarily physical industries-exploring the impact of digital trends on business models of automobile manufacturers," Wirtschaftsinformatik, vol. 88, no. 3-5, pp. 1313-1327, 2015.

[32] W. J. Martin, The Global Information Society, Taylor \& Francis, New York, NY, USA, 2015.

[33] E. Ziemba, "The contribution of ICT adoption to the sustainable information society," Journal of Computer Information Systems, vol. 59, no. 2, pp. 116-126, 2019.

[34] I. Castelo-Branco, F. Cruz-Jesus, and T. Oliveira, “Assessing industry 4.0 readiness in manufacturing: evidence for the European union," Computers in Industry, vol. 107, pp. 22-32, 2019.

[35] H. Lasi, P. Fettke, H.-G. Kemper, T. Feld, and M. Hoffmann, "Industry 4.0," Business \& Information Systems Engineering, vol. 6, no. 4, pp. 239-242, 2014.

[36] M. Ghobakhloo, "The future of manufacturing industry: a strategic roadmap toward Industry 4.0," Journal of Manufacturing Technology Management, vol. 29, no. 6, pp. 910-936, 2018.

[37] M. E. Porter and V. E. Millar, "How information gives you a competitive advantage," Harvard Business Review, vol. 63, no. 4, pp. 149-160, 1985.

[38] J. Vega-Jurado, A. Gutierrez-Gracia, and I. Fernandez-deLucio, "Does external knowledge sourcing matter for innovation? Evidence from the Spanish manufacturing industry," Industrial and Corporate Change, vol. 18, no. 4, pp. 637-670, 2009.

[39] A. M. Pettigrew, H. Thomas, and R. Whittington, Handbook of Strategy and Management, SAGE, Newcastle upon Tyne, UK, 2001.

[40] W. J. Doll and M. A. Vonderembse, "Forging a partnership to achieve competitive advantage: the CIM challenge," MIS Quarterly, vol. 11, no. 2, pp. 205-220, 1987.

[41] Y. Merali, T. Papadopoulos, and T. Nadkarni, "Information systems strategy: past, present, future?" The Journal of Strategic Information Systems, vol. 21, no. 2, pp. 125-153, 2012.

[42] Y. Qi, K. K. Boyer, and X. Zhao, "Supply chain strategy, product characteristics, and performance impact: evidence from Chinese manufacturers," Decision Sciences, vol. 40, no. 4, pp. 667-695, 2014.

[43] S. Qrunfleh and M. Tarafdar, "Supply chain information systems strategy: impacts on supply chain performance and 
firm performance," International Journal of Production Economics, vol. 147, pp. 340-350, 2014.

[44] T. Paschou, M. Rapaccini, F. Adrodegari, and N. Saccani, "Digital servitization in manufacturing: a systematic literature review and research agenda," Industrial Marketing Management, vol. 89, pp. 278-292, 2020.

[45] S. Mithas, A. Tafti, A. Tafti, and W. Mitchell, "How a firm's competitive environment and digital strategic posture influence digital business strategy," MIS Quarterly, vol. 37, no. 2, pp. 511-536, 2013.

[46] F. Mahut, J. Daaboul, M. Bricogne, and B. Eynard, "Productservice systems for servitization of the automotive industry: a literature review," International Journal of Production Research, vol. 55, no. 7, pp. 2102-2120, 2017.

[47] T. Grubic, "Remote monitoring technology and servitization: exploring the relationship," Computers in Industry, vol. 100, pp. 148-158, 2018.

[48] A. Rymaszewska, P. Helo, and A. Gunasekaran, "IoT powered servitization of manufacturing - an exploratory case study," International Journal of Production Economics, vol. 192, pp. 92-105, 2017.

[49] J. Ukko, M. Nasiri, M. Saunila, and T. Rantala, "Sustainability strategy as a moderator in the relationship between digital business strategy and financial performance," Journal of Cleaner Production, vol. 236, Article ID 117626, 2019.

[50] P. Schneider, "Managerial challenges of Industry 4.0: an empirically backed research agenda for a nascent field," $R e-$ view of Managerial Science, vol. 12, no. 3, pp. 803-848, 2018.

[51] U. Reisgen, S. Mann, K. Middeldorf, R. Sharma, G. Buchholz, and $\mathrm{K}$. Willms, "Connected, digitalized welding productionIndustrie 4.0 in gas metal arc welding," Welding in the World, vol. 63 , no. 4, pp. 1121-1131, 2019.

[52] R. Lozano, "Envisioning sustainability three-dimensionally," Journal of Cleaner Production, vol. 16, no. 17, pp. 1838-1846, 2008.

[53] E. Kristoffersen, F. Blomsma, P. Mikalef, and J. Li, "The smart circular economy: a digital-enabled circular strategies framework for manufacturing companies," Journal of Business Research, vol. 120, pp. 241-261, 2020.

[54] C. J. C. Jabbour, A. B. L. d. S. Jabbour, J. Sarkis, and M. G. Filho, "Unlocking the circular economy through new business models based on large-scale data: an integrative framework and research agenda," Technological Forecasting and Social Change, vol. 144, pp. 546-552, 2019.

[55] M. Iansiti and K. R. Lakhani, "Digital ubiquity: how connections, sensors, and data are revolutionizing business," Harvard Business Review, vol. 92, no. 11, p. 19, 2014.

[56] M. Hock, T. Clauss, and E. Schulz, "The impact of organizational culture on a firm's capability to innovate the business model," R \& D Management, vol. 46, no. 3, pp. 433-450, 2016.

[57] C. S. Chapman and L.-A. Kihn, "Information system integration, enabling control and performance," Accounting, Organizations and Society, vol. 34, no. 2, pp. 151-169, 2009.

[58] A. S. Maiga, A. Nilsson, and F. A. Jacobs, "Assessing the interaction effect of cost control systems and information technology integration on manufacturing plant financial performance," The British Accounting Review, vol. 46, no. 1, pp. 77-90, 2014.

[59] A. Bharadwaj, E. Sawy, O. A. El Sawy, P. A. Pavlou, and N. Venkatraman, "Digital business strategy: toward a next generation of insights," MIS Quarterly, vol. 37, no. 2, pp. 471-482, 2013. 